\title{
Marfan syndrome in children and adolescents: predictive and prognostic value of aortic root growth for screening for aortic complications
}

\author{
M Groenink, L Rozendaal, M S J Naeff, R C M Hennekam, A A M Hart, \\ E E van der Wall, B J M Mulder
}

\begin{abstract}
Objective-To assess and measure the diagnostic and prognostic value of individual aortic root growth in children and adolescents with Marfan syndrome. Design-From 1983 to 1996, 250 children were screened for Marfan syndrome. Serial echocardiographic aortic root measurements of 123 children (57 Marfan, 66 control) were available for evaluation of aortic root growth. Aortic root diameters were correlated with body surface area. Based on individual growth of the aortic root a discrimination formula was derived to distinguish Marfan patients from control subjects.

Results-Sensitivity and specificity of this method, which were dependent on the number of measurements, were $84 \%$ and $73 \%$, respectively, for three serial measurements. The discrimination score also predicted a five year complication free survival in all patients.

Conclusions-In children and adolescents with Marfan syndrome, aortic root growth differs significantly from subjects in whom Marfan syndrome was definitely ruled out during screening. Measurement of individual aortic root growth may serve to establish diagnosis at an early stage and is of prognostic value for occurrence of aortic complications.

(Heart 1998;80:163-169)
\end{abstract}

Keywords: Marfan syndrome; aortic root growth; echocardiography; children; adolescents

Marfan syndrome is an autosomal dominantly inherited disorder of connective tissue associated with mutations in the fibrillin I gene, ${ }^{1}$ in which ocular, skeletal, cardiovascular, integumentary, pulmonary, and neurological features may be present in a highly variable degree. ${ }^{2}{ }^{3}$ Until recently, the diagnosis was based on fulfilment of diagnostic criteria established in Berlin in 1986. ${ }^{4}$ In 1995 these criteria were revised in Gent. ${ }^{5}$ Prevalence has been estimated to be 1 in 3000 to $5000,{ }^{6} 15-30 \%$ of whom represent new mutations. ${ }^{347}$

Prognosis is mainly determined by progressive aortic root dilatation, potentially leading to aortic type A dissection and aortic rupture, which are the major causes of death. ${ }^{2} 3$ Prophylactic composite graft repair of the aortic root is usually performed before the aortic root diameter reaches $55 \mathrm{~mm}$ in adults, thereby raising life expectancy from 40 years in 1972 to approximately 60 years in $1993 .{ }^{8}$ Nevertheless, $60 \%$ of all mortality is still caused by aortic complications $^{9}$ and hence several studies with respect to aortic complications have been focused on the identification of specific risk groups in the Marfan population..$^{10}{ }^{11}$

Whereas aortic root complications are rare in childhood, early identification of the diagnosis of Marfan syndrome and the identification of patients at a high risk for aortic complications are still important. Particularly in childhood, clinical signs vary in onset and severity, and long term follow up examinations may be necessary before a definite diagnosis can be established. ${ }^{12}$ Furthermore, treatment with $\beta$ adrenergic blocking agents, which are reported to slow down the rate of aortic dilatation, ${ }^{13}{ }^{14}$ should be started as soon as possible to delay or even prevent critical dilatation requiring surgical intervention. Although the beneficial effects of this treatment on the aortic root dilatation rate have only been investigated in adults, one could argue that the same protective mechanism occurs in children. Thus, since 1996 we have increasingly prescribed $\beta$ blocker treatment for Marfan children in our institution. We perform prophylactic surgery at an aortic root diameter of $50 \mathrm{~mm}$.

Screening in children relies mainly on aortic root size. Aortic root diameter is measured by echocardiography at the sinuses of Valsalva and related to height, ${ }^{15}{ }^{16}$ weight, ${ }^{16}{ }^{17}$ and body surface area, ${ }^{14}{ }^{16}{ }^{18-23}$ the latter being considered as the most significant reference in children and adolescents. ${ }^{19}{ }^{21-27}$ With serial measurements of the aortic root diameter, individual aortic root growth curves can be constructed. Our aim in this study was threefold: (1) to assess individual growth of the aortic root diameter relative to body surface area; (2) to predict at an early stage a probable diagnosis of Marfan syndrome by measuring individual aortic root growth; and (3) to examine the prognostic importance of aortic root growth on aortic complications in children and adolescents with Marfan syndrome.

\section{Methods}

POPULATION

From 1983 until 1996, 250 children have been referred to the multidisciplinary Marfan team of the Academic Medical Centre of Amsterdam. Indications for screening included family history, excessive height, chest or spine anomalies, hypermobile joints, and lens luxation. 
Table 1 Numbers of children evaluable for analysis of 250 children referred for screening

\begin{tabular}{|c|c|c|c|}
\hline & Marfan & Not Marfan & Uncertain \\
\hline & 71 & 104 & 75 \\
\hline Excluded from analysis & $14^{\star}$ & $38+$ & \\
\hline Study population & 57 & 66 & \\
\hline \multicolumn{4}{|c|}{ Echocardiographic measurements per subject } \\
\hline$\geqslant 2$ & 57 & 66 & \\
\hline$\geqslant 3$ & 46 & 34 & \\
\hline$\geqslant 4$ & 40 & 16 & \\
\hline
\end{tabular}

ॠ 12 patients with incomplete data and two patients above 21 years of age.

†32 control subjects with incomplete data, one control subject above 21 years of age, two control subjects with coarctation of the aorta, one control subject with aortic valve stenosis, one control subject with Ehlers-Danlos type IV, and one control subject with idiopathic aortic dilatation and atrial septal defect.

None of these subjects was referred for aortic root enlargement. Of the 250 children, 71 eventually had a definite diagnosis of Marfan syndrome according to the Berlin criteria ${ }^{4}$ and in 104 the diagnosis Marfan syndrome could definitely be excluded on clinical grounds at some time during this 13 year period. A control group excluded any child with aortic disease or connective tissue disease. In 75 children the diagnosis remained uncertain, which also prevented inclusion in the study.

Of 175 children initially included, 52 were ruled out for various reasons (table 1), leaving 123 children for final analysis (57 Marfan patients and 66 controls). None of these 123 children had ever used $\beta$ blocking agents because up to 1996 no obvious advantage of this treatment in children with Marfan syndrome was recognised in our institution. In the Marfan group, four patients (7\%) were diagnosed before the third year of age. Mean age at definite diagnosis in the entire Marfan group was 7 years (range 1 to 18 years). Follow up was continued until the subjects reached 21 years of age. The baseline characteristics of the study population, expressed as ranges and means (SD), are shown in table 2.

\section{ECHOCARDIOGRAPHY}

Echocardiographic measurements of the aortic root diameter of the patients and control subjects were made by M mode echocardiography and cross sectional echocardiography. The number of measurements per patient and control subject varied from two to 19 (mean (SD) 6.6 (3.9)) and from two to six (3.1 (1.2)), respectively. We measured the aortic root at the level of the sinuses of Valsalva with both methods. The measurements by M mode echocardio-

Table 2 Clinical characteristics

\begin{tabular}{|c|c|c|c|c|c|}
\hline & \multicolumn{2}{|c|}{ Patients $(n=57)$} & \multicolumn{2}{|c|}{ Control subjects $(n=66)$} & \multirow[b]{2}{*}{$p$ values } \\
\hline & Range & Mean (SD) & Range & Mean (SD) & \\
\hline Male/female (\%) & & $51 / 49$ & & $49 / 51$ & \\
\hline Age of first echo (years) & 1.0 to 16.6 & $8.4(4.6)$ & 1.4 to 15.7 & $10.1(3.5)$ & $<0.05$ \\
\hline $\begin{array}{l}\text { Years of follow up } \\
\text { Body surface area }\left(\mathrm{m}^{2}\right)\end{array}$ & 0.2 to 14.4 & $5.6(3.2)$ & 1.0 to 9.6 & $4.0(2.0)$ & $<0.01$ \\
\hline \multicolumn{6}{|l|}{ Body surface area $\left(\mathrm{m}^{2}\right)$} \\
\hline $\begin{array}{l}\text { First echo } \\
\text { Growth }\end{array}$ & $\begin{array}{l}0.36 \text { to } 1.93 \\
0.05 \text { to } 1.11\end{array}$ & $\begin{array}{l}1.17(0.41) \\
0.48(0.30)\end{array}$ & $\begin{array}{l}0.51 \text { to } 1.96 \\
0.06 \text { to } 1.04\end{array}$ & $\begin{array}{l}1.26(0.34) \\
0.36(0.23)\end{array}$ & $\begin{array}{l}\text { NS } \\
<0.05\end{array}$ \\
\hline \multicolumn{6}{|l|}{ Diameter Ao $(\mathrm{mm})$} \\
\hline First echo & 19 to 42 & $29(5)$ & 17 to 35 & $24(4)$ & $<0.0001$ \\
\hline Growth & -1.7 to 41 & $8(7)$ & -1 to 11.5 & $3(3)$ & $<0.0001$ \\
\hline
\end{tabular}

Values are shown as range and mean (SD) unless otherwise specified.

Ao, aortic root diameter at the sinuses of Valsalva; Growth, from first until most recent measurement. graphy were made according to the recommendations of the American Society of Echocardiography (ASE) ${ }^{28}$ and guided by cross sectional mode. With cross sectional echocardiography the aortic root diameter was imaged in long axis parasternal views.

We used all the measurements made by both modes interchangeably, because in an earlier study from our institution ${ }^{29}$ no clinically relevant difference was found in assessing the aortic root diameter by either of these two echocardiographic methods.

\section{INDIVIDUAL AORTIC ROOT GROWTH CURVES}

To construct aortic root growth curves we first calculated body surface area by the Dubois formula. ${ }^{30}$ Aortic root diameters from each individual were then correlated with body surface area to yield aortic root growth curves. Previous studies have shown that individual growth curves related to body surface area can be described by means of linear regression analysis. ${ }^{19} 262731$ Differences in individual aortic root growth between patients and control subjects were analysed by individual specific intercepts and slopes from linear regression lines, resulting in a discrimination formula to predict Marfan syndrome (see statistical analysis below). To examine the possible value of aortic root growth in addition to absolute dilatation for early diagnosis, we selected 26 Marfan patients who had had at least three echocardiographic measurements before dilatation of the aortic root occurred. The discrimination formula was used to identify aortic root involvement in these 26 patients, based on the aortic root growth before the aortic root became dilated. We used the nomogram previously reported by our group ${ }^{29}$ to examine whether the aortic root was dilated. This was done to rule out the effects of differences in anthropometric measurements and growth rate between a population being screened for Marfan syndrome and a standard population, which we showed in a previous study. ${ }^{29}$

\section{RISK STRATIFICATION}

The discrimination formula was also tested to predict increased risk for aortic complications in the Marfan group. End points were defined as cardiovascular death, aortic root surgery for dissection or rupture of the ascending aorta, and critical ascending aortic root dilatation beyond $50 \mathrm{~mm}$ in children requiring prophylactic repair of the aortic root. Aortic root growth was not considered to be a standard indication for prophylactic surgery in our institution. In Marfan patients we calculated the complication rate from the second echocardiographic measurement in relation to the discrimination score.

\section{STATISTICAL ANALYSIS}

Data on baseline characteristics and serial echocardiographic measurements are presented as range and mean (SD) unless otherwise reported. The differences of the mean values were compared with the Student's $t$ test. In all 123 children the individual aortic root growth curve in relation to body surface area was exam- 


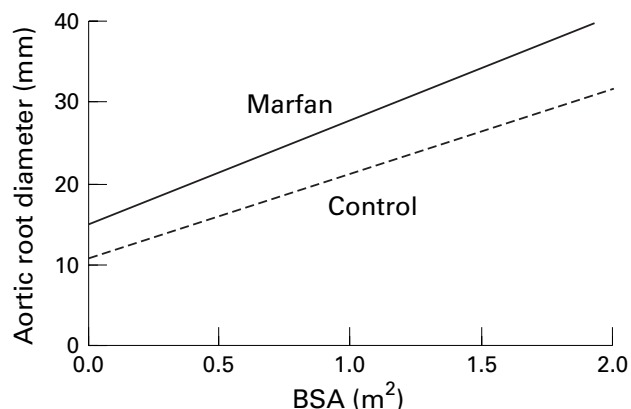

Figure 1 Regression lines of mean aortic root growth in relation to body surface area (BSA) of the Marfan patients $(n=57)$ and the control subjects $(n=66)$.

ined and quantified using linear regression analysis. The relation between aortic root diameter and body surface area was analysed using a random coefficient linear growth model. ${ }^{32}$ "Proc.mixed" from SAS 6.11 for Windows was used for the calculations. Differences in individual aortic root growth between patients and control subjects were analysed by individualspecific intercepts and slopes, following quadratic discriminant analysis. ${ }^{33}$ This statistical model was modified to take into account differences between subjects regarding the precision of the intercepts and slopes caused by the different numbers of measurements per subjects and the differences in body surface area values. The analysis resulted in a discriminant score function, which includes the slope and intercept, number of measurements, and mean and standard deviation of body surface area of a subject. Further details are given in the appendix.

Depending on a chosen cut off point an optimal balance between the sensitivity and specificity of the discrimination score can be obtained. A cut off point at -0.7 of the discrimination score was chosen, indicating that a score larger than -0.7 was predictive of Marfan syndrome - that is, involvement of the aortic root-while a score below -0.7 indicated absence of aortic root disease. We examined the sensitivity and specificity for subjects with at least two, three, and four serial measurements, respectively, at the cut off point of -0.7 .

The log rank test was used to test the differences in complication rate between the patients stratified according to the score. The complication-free event rate was expressed in percentages with one standard error (SE). To obtain similar sample sizes, two approximate groups were prespecified to define the categories in the plot: 29 patients with a discrimination score of less than 2 , and 28 patients with a score above 2 .

All analyses including aortic growth rate and risk stratification were made in SPSS 6.0. A p value $<0.05$ was considered significant.

\section{Results}

ANALYSIS OF GROWTH

In all 123 children the individual growth curves were analysed in relation to body surface area. The mean interval between measurements was significantly shorter for the Marfan group than for the controls (Marfan $1.3(0.7)$ years $v$ control $2.3(0.9)$ years, $\mathrm{p}<0.01)$ ) but there were

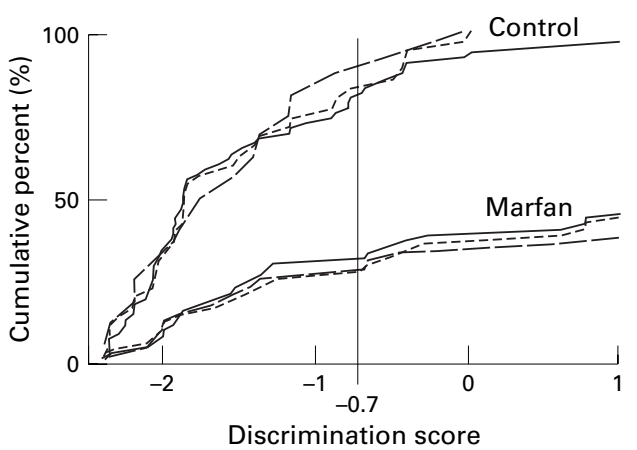

Figure 2 Cumulative percentage plot of discrimination score of patients and control subjects with at least two (uninterrupted line), three (short dashes), and four (long dashes) measurements per subject. The cut off point at -0.7 shows a different sensitivity and specificity for at least two ( $81 \%$ and $69 \%$, respectively), three (84\% and $73 \%$, respectively) and four ( $90 \%$ and $73 \%$, respectively) measurements.

no significant differences within the groups between subjects with two, three, or more measurements. The mean regression line of the 57 patients was steeper than in the 66 control subjects and there was a significant discrimination between the two different groups $(y=13.4 x+14.5$ and $y=9.3 x+12.1$ respectively, $\mathrm{p}<0.001)$. The mean regression lines for growth of the aortic root in relation to body surface area are shown in fig 1 .

DISCRIMINATION SCORE

At a cut off point of -0.7 (fig 2), the diagnostic accuracy for the subjects with at least two, three, and four serial echocardiographic measurements was examined. For subjects with at least two serial measurements the observed sensitivity and specificity were $81 \%$ and $69 \%$ respectively; for subjects with at least three serial measurements, $84 \%$ and $73 \%$ respectively; and for subjects with at least four serial measurements, $90 \%$ and $73 \%$ respectively.

Of the 46 patients with at least three serial measurements, 26 showed no aortic root dilatation during the first three measurements. Among these 26 patients, abnormal aortic root growth was identified in 18 by means of the discrimination formula $(69 \%)$, suggesting Marfan syndrome before aortic root dilatation.

RISK STRATIFICATION

During 13 years' follow up, 12 patients developed complications in the cardiovascular system (table 3). At five years' follow up after the second echocardiographic measurement, the estimated probabilities of no complications were $100 \%(\mathrm{SE}=0 \%)$ for a score $<2$, and $85 \%(\mathrm{SE}=7 \%)$ for a score $\geqslant 2$. At 10 years' follow up after the second echocardiographic measurement these figures were $90 \%$ $(\mathrm{SE}=9 \%)$ for a score $<2$, and $56 \%$ $(\mathrm{SE}=13 \%)$ for a score $\geqslant 2, \mathrm{p}=0.069$ (fig 3).

Table 4 shows data on the family history of Marfan syndrome and aortic dissection of the two different risk groups (score $\geqslant 2$ and score $<2$ ). Patients with a score $\geqslant 2$ were younger (9.4 (5.1) and 10.2 (4.6) years, respectively), less often had a positive family history of Mar- 
Table 3 Discrimination score of 12 patients with aortic complications

\begin{tabular}{llccrr}
\hline Patient & End point & $\begin{array}{l}\text { Aortic root } \\
\text { diameter }(\mathrm{mm})\end{array}$ & $\begin{array}{l}\text { BSA } \\
\left(\mathrm{m}^{2}\right)\end{array}$ & $\begin{array}{l}\text { Age } \\
\text { (years) }\end{array}$ & $\begin{array}{l}\text { Discrimination } \\
\text { score }\end{array}$ \\
\hline 1 & Prophylactic repair & 50.8 & 1.41 & 9.0 & 373.0 \\
2 & Prophylactic repair & 83.0 & 2.02 & 19.0 & 343.5 \\
3 & Cardiovascular death & 58.5 & 1.35 & 12.0 & 22.1 \\
4 & Aortic dissection type A & ND & ND & 21.0 & 6.4 \\
5 & Aortic dissection type A & 58.0 & 1.75 & 26.0 & 14.7 \\
6 & Prophylactic repair & $>50.0$ & 1.97 & 19.0 & 8.6 \\
7 & Prophylactic repair & 50.5 & 1.95 & 21.0 & -0.6 \\
8 & Prophylactic repair & 53.5 & 1.85 & 18.5 & -1.9 \\
9 & Cardiovascular death & 25.0 & 0.49 & 1.5 & 2.7 \\
10 & Prophylactic repair & $>50.0$ & 1.88 & 18.5 & 36.1 \\
11 & Prophylactic repair & 48.0 & 1.73 & 16.0 & 65.3 \\
12 & Prophylactic repair & 55.0 & 1.86 & 26.0 & 11.0 \\
\hline
\end{tabular}

BSA, body surface area; ND, no data available.

Table 4 Comparison of clinical findings in 57 patients with a discrimination score $\geqslant 2$ and $<2$

\begin{tabular}{llll}
\hline Features & $\begin{array}{l}\text { Score } \geqslant 2 \\
(n=28)\end{array}$ & $\begin{array}{l}\text { Score }<2 \\
(n=29)\end{array}$ & p value \\
\hline Mean (SD) age at second echo (years) & $9.4(5.1)$ & $10.2(4.6)$ & 0.54 \\
Mean (SD) follow up after second echo (years) & $6.2(3.4)$ & $4.9(2.9)$ & 0.13 \\
Male/female (\%) & $61 / 39$ & $41 / 59$ & 0.15 \\
Aortic complications* (\%) & 36 & 7 & 0.07 \\
Family history positive for Marfan syndrome (\%) & 60 & 83 & 0.06 \\
Family history positive for aortic dissection (\%) & 36 & 21 & 0.13 \\
Severe skeletal features (\%) & 29 & 52 & 0.07 \\
Ectopia lentis (\%) & 54 & 45 & 0.51 \\
Mitral valve prolapse (\%) & 96 & 72 & 0.01
\end{tabular}

^As defined end points (from Kaplan-Meier).

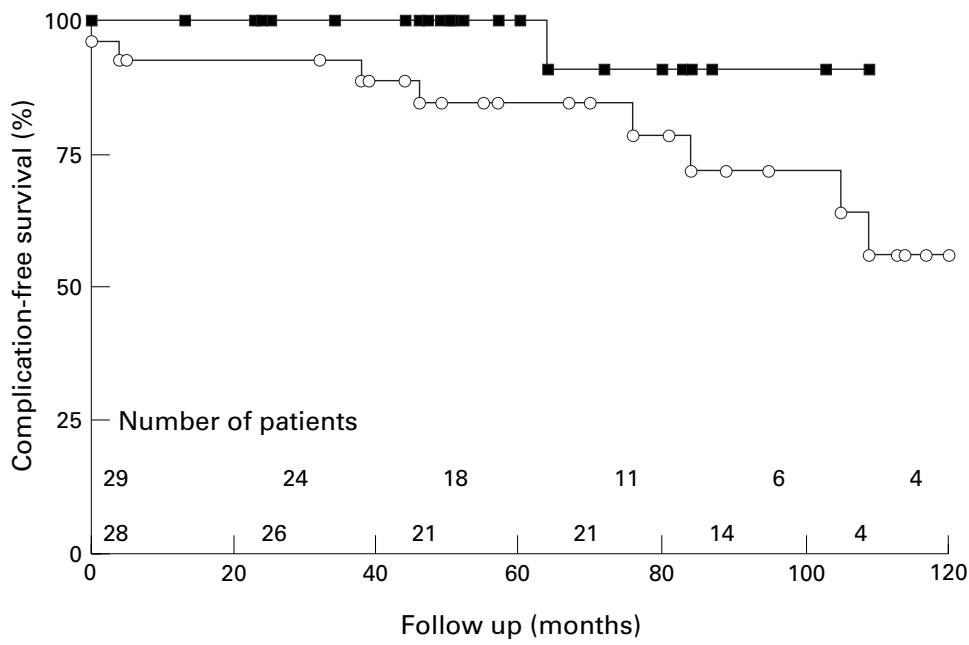

Figure 3 Complication rate for the patients in relation to the discrimination scores distinguishing two groups of similar sample size. The numbers of patients in each group on whom the calculations are based are given at the bottom. Patients with a discrimination score $<2(n=29)$ filled squares; patients with a score $\geqslant 2(n=28)$ empty circles.

fan syndrome ( $60 \%$ and $83 \%$, respectively), and more often had a positive family history of aortic dissection (36\% and $21 \%$, respectively), compared with patients with a score $<2$.

\section{Discussion}

Marfan syndrome remains a difficult nosological entity requiring a multidisciplinary approach in specialised centres. Our study shows that with a formula based on paired echocardiographic and anthropometric data, measurement of aortic root growth may establish the diagnosis at an early stage, and predict aortic complications in children and adolescents with Marfan syndrome.

An early diagnosis may be important but is still often not easily made. In our population of 250 children who were initially referred for screening, the diagnosis of Marfan syndrome could not be established with absolute certainty in a substantial group (75 subjects) after a follow up of several years (range 0 to 11 ; mean 2 years). This indicates the difficulty in establishing the diagnosis Marfan syndrome using the standard diagnostic criteria. Hence additional information that can provide a tool for diagnosis at an earlier stage is of great importance. For the purpose of the present study we selected only those patients in whom no doubt remained about the diagnosis of Marfan syndrome. Subsequent studies will have to be performed to evaluate the formula in patients in whom the diagnosis remains questionable.

The relation of aortic root growth to body surface area has previously been analysed in 17 Marfan patients by Hirata $e t a l^{34}$ and in 19 children with Marfan syndrome by Vetter et al. ${ }^{26}$ In these small groups of patients a positive correlation was found between initial aortic root dilatation and the rate of aortic growth. In 89 Marfan patients studied by Legget et al an aortic diameter of $30 \%$ or more above normal was found to be related to an increased risk of aortic complications. ${ }^{11}$ Furthermore, in 62 Marfan patients studied by serial echocardiograms, an annual change in aortic diameter of more than $5 \%$ appeared to be a risk factor for aortic complications. ${ }^{11}$

Identification of a higher risk group during follow up is important and may have implications for management and treatment. The prevalence of serious cardiovascular complications in childhood is low (4.3\% of 186 patients as reported by El Habbal ${ }^{35}$ ). There is, however, a risk of rupture or dissection of the aorta around adolescence (approximately $20 \%) .{ }^{10113536}$

Our Marfan population could be divided into two groups with different growth rates. Patients with a higher growth rate-that is, with a score $\geqslant 2$ and a higher risk of aortic complications - were younger at initial evaluation, less often had a positive family history of Marfan syndrome, and more often had a family history of aortic dissection than patients with a score $<2$. This is in line with previous studies that showed that new mutations, younger age at presentation, and a family history of severe aortic disease in Marfan patients are important predictors of aortic complications. ${ }^{703334}$ There was a significant discrimination in the occurrence of mitral valve prolapse between the two groups $(p=0.01)$. No other studies, however, showed a correlation between the occurrence of mitral valve prolapse and aortic complications in Marfan syndrome. Therefore the significance of this feature remains unclear. More accurate measurements of aortic root diameter with magnetic resonance imaging (MRI) may improve the predictive power of aortic root growth in Marfan syndrome. ${ }^{37}$ Further specification of diagnostic criteria, for instance skeletal features and dural ectasia as proposed by De Paepe et $a l,{ }^{5}$ may also make diagnosis easier. Until a fully reliable molecular based approach that will identify patients at higher 
cardiovascular risk is widely available, echocardiographic and MRI variables will be the most important prognostic indicators. Patients with Marfan syndrome and a discrimination score $\geqslant 2$ should be followed closely, because of the increased risk of serious complications.

None of the study subjects used $\beta$ blocking agents before or during our study. Whether the use of these drugs would have invalidated the discrimination score can only partly be answered by making assumptions on theoretical grounds, as no research in this specific direction has yet been performed. Aortic dilatation in Marfan syndrome will occur when degenerative changes take place in the aortic tunica media, with defragmentation of elastic tissue and mucoid pooling. These alterations in the tunica media resemble degenerative changes in the elderly, ${ }^{38}{ }^{39}$ and gradual aortic dilatation (with the risk of aortic dissection or rupture) also takes place when people grow older. Thus media changes in the Marfan aorta could be regarded as accelerated aging. We do not know to what extent this is the case in children with Marfan syndrome. When tests of elasticity are performed in vivo (by measuring distensibility), the aorta is found to be less elastic in Marfan patients and in the elderly, independent of aortic size. ${ }^{40}{ }^{41}$ However, in the few studies that have been performed to test the effect of $\beta$ blocking agents on aortic elasticity in children with Marfan syndrome, no significant difference in aortic distensibility between those with and without $\beta$ blocker treatment was shown. ${ }^{42}$ If we assume that aortic dilatation will follow decreased aortic elastic function, no effect of $\beta$ blocking agents on aortic root growth in children is to be expected, and the value of the discrimination formula will be unaffected. Knowing, on the other hand, that $\beta$ blocking agents can reduce aortic dilatation in adult Marfan patients and that Marfan syndrome is characterised by a great variability in clinical features, there might be a subgroup of children with Marfan syndrome in whom $\beta$ blocker treatment results in decreased aortic growth rate. This would, of course, have an effect on the validity of the discrimination formula.

\section{STUDY LIMITATIONS}

The number of patients with aortic complications may have been too small to assess the true prognostic value, as can be seen from the large standard errors. There is, however, a clear trend with respect to the occurrence of aortic complications and the family history. Furthermore, rapid growth of the aortic root could incidentally have played a role in the decision to perform prophylactic surgery.

One could argue that there was no absolute certainty of excluding Marfan syndrome on clinical grounds during a screening period. Moreover, there is a possibility that Marfan patients were diagnosed after the 21 st year of age and wrongly classified as controls in our study. As Lipscomb et al have recently shown, ${ }^{43}$ the variance in evolving Marfan phenotype causes diagnostic problems in childhood. Most patients in their study were, however, diagnosed before their 15th year and it seems reasonable to assume that there will be very few patients in whom the signs are not present after the 21st year (when growth ceases to be an important disturbing factor). As stated, patients in whom any doubt remained were excluded from analysis. If, however, any patients were wrongly left in the control group, the true difference between the two groups could only be more clear than we showed in the current study.

As can be seen from table 2, follow up was significantly shorter in the control group than in the Marfan group, which could involve a possible source of error. A subject classified as a control might, when followed for a longer period, develop aortic dilatation. Mean age at the end of follow up, however, was the same (14 years) in both groups (table 2) and most patients will be diagnosed before that age. Moreover, as the mean interval between measurements was larger for the control subjects, one could argue that aortic root growth rate was investigated more reliably in the controls, which would counterbalance the shorter period of follow up.

In our study, the sensitivity and specificity of the diagnosis of Marfan syndrome, based on aortic root growth, are favourably reflected in the population from which the calculation variables were taken. The cut off point was chosen to achieve an optimal balance between sensitivity and specificity in the test population, which was also the study population. It is thus to be expected that the discriminating power will be somewhat lower when our score function is applied to an independent dataset, but to what extent it is difficult to estimate owing to the rather complex statistical methods. Our discrimination formula may still need to be tested in a different Marfan population to find true sensitivity and specificity values.

Another limitation of the study is the relatively complex nature of the discrimination formula, which necessitates the use of computerised assistance in daily clinical practice. On the other hand, the importance of early and accurate diagnosis might justify such an additional effort. In our hands, the proper score and subsequent diagnosis could be established within five minutes using a hand held calculator.

\section{CONCLUSIONS}

We conclude that the individual growth rate of the aortic root of Marfan patients is significantly greater than in controls without Marfan syndrome. Quantification of individual aortic root growth using a newly developed formula may serve to establish the diagnosis at an early stage and is of prognostic value with respect to the occurrence of aortic complications in children and adolescents with Marfan syndrome. 


\section{Appendix}

BASIC METHOD

The individual aortic root growth curves related to body surface area are described as linear regression lines:

$$
\mathrm{AoD}_{\mathrm{ij}}=\mathrm{a}_{\mathrm{i}}+\mathrm{b}_{\mathrm{i} *} \mathrm{BSA}_{\mathrm{ij}}+\mathrm{e}_{\mathrm{ij}}
$$

where $\mathrm{Ao}_{\mathrm{Dij}}$ is the aortic root diameter of subject $i$ at evaluation day $\mathrm{j}, \mathrm{BSA}_{\mathrm{ij}}$ is the body surface area of subject $i$ at evaluation day $j, a_{i}$ is the intercept of the regression line of subject $i$, $b_{i}$ is the slope of the regression line of subject $i$, and $e_{i j}$ is the deviation of point $j$ for subject $i$ from the subject specific regression line given by $a_{i}$ and $b_{i}$.

One can plot the observed $b_{i}$ values versus $a_{i}$ values for both Marfan patients and control subjects. If it is possible to discriminate between Marfan patients and control subjects on the basis of the aortic root growth curves, one may expect to find two clusters of points in such a plot-one for the patients and one for the control subjects. Hence one can try to find a line that optimally separates the two clusters. The prediction would be that a subject is a Marfan patient (or control subject) if his $\left(\mathrm{a}_{\mathrm{i}}, \mathrm{b}_{\mathrm{i}}\right)$ point lies on the same side of the line as the Marfan (or control subject) cluster.

Similarly, the dividing line can be described by the equation $e=c_{\star} a_{i}+d_{\star} b_{i}$, where e is the cut off point, and $\mathrm{c}$ and $\mathrm{d}$ are coefficients. For each subject one can calculate a discrimination score and predict that the subject will be a Marfan patient if the result is larger than e or a control subject if the result is lower than e. One way to find such a dividing line is by means of quadratic discriminant analysis. ${ }^{31}$ In that method, the coefficients c, d, and e are calculated from the means, standard deviations, and correlations of the $a_{i}$ and $b_{i}$ values within each group. However, all points are assumed to have the same precision. This is not the case in the present study design, because different subjects have different numbers of points at different values of body surface area, resulting in different precisions of the $a_{i}$ and $b_{i}$ values. Two sources of variation have to be taken into account: (1) variations of points around the regression line within subjects, and (2) variations of the regression lines $\left(a_{i}\right.$ and $\left.b_{i}\right)$ between subjects. With regard to the latter, it was assumed that this variation within each group (Marfan patients and control subjects) can be described by a bivariate normal distribution, one for each group.

Within a subject, the aortic root diametersgiven the body surface area values - are assumed to be independently normally distributed, with a standard deviation only depending on the group. The effect of this within subject variation on the standard deviations and the correlation of the observed $a_{i}$ and $b_{i}$ values can be calculated by standard methods, as can the combined effect of the within subject and between subject variation. The result is a modified Fisher discriminant score function, that is a log likelihood ratio based on a bivariate normal distribution using the same basic formula as in Fisher's discriminant analysis, but substituting adapted values for the stand-
Table 5 Estimates (SE) derived from the data for Marfan syndrome patients and controls

\begin{tabular}{lcc}
\hline Parameter & Marfan patients & Control subjects \\
\hline$\alpha_{\mathrm{g}}$ & $14.51(0.90)$ & $12.68(0.85)$ \\
$\beta_{\mathrm{g}}$ & $13.38(0.85)$ & $9.27(0.63)$ \\
$\sigma_{a, \mathrm{~g}}$ & 2.64 & 3.60 \\
$\sigma_{\beta, \mathrm{g}}$ & 4.49 & 3.12 \\
$\sigma_{\alpha \beta, \mathrm{g}}$ & -4.59 & -9.58 \\
$\sigma_{\varepsilon, \mathrm{g}}$ & 2.60 & 1.38 \\
\hline
\end{tabular}

ard deviations and correlations. The necessary parameters are derived from the data using restricted maximum likelihood (REML) estimation in a random coefficient linear growth curve model, ${ }^{36}$ using a different model for each group. Calculations were performed using the SAS 6.11 procedure "Proc Mixed."

FORMULAS FOR THE DISCRIMINATION SCORE

The following symbols are used:

$\mathrm{N}$, number of (aortic root diameter $v$ body surface area) points for a subject

$\mathrm{m}$, mean value of body surface area for a subject

s, SD of body surface area for a subject

a, intercept of the regression line for a subject

b, slope of the regression line for a subject

g, group (Marfan patients or control subjects) $\alpha_{g}$, mean intercept for group $\mathrm{g} \beta_{\mathrm{g}}$, mean slope for group $\mathrm{g} \sigma_{a, g}$, population SD of intercept in group $\mathrm{g} \sigma_{\beta, g}$, population $\mathrm{SD}$ of slope in group $\mathrm{g} \sigma_{\alpha \beta, \mathrm{g}}$, population covariance of intercept and slope in group $\mathrm{g} \sigma_{\varepsilon g}$, SD of point from regression line in group $\mathrm{g}$

$\ln (\mathrm{x})$, natural $\log$ of $\mathrm{x}$.

The estimates showed in table 5 are derived from the data using REML estimation in a random coefficient linear growth curve model. The following formulas can then be used to calculate the discrimination score for each subject:

(1) $\mathrm{V}_{11}=1 / \mathrm{N}+\mathrm{m}^{2} /(\mathrm{N}-1) \mathrm{s}^{2}$

(2) $V_{12}=-m /(N-1) s^{2}$

(3) $\mathrm{V}_{22}=1 /(\mathrm{N}-1) \mathrm{s}^{2}$

(4) $Z_{11, \mathrm{~g}}^{22}=\sigma_{a, \mathrm{~g}}^{2}+\sigma_{\varepsilon, \mathrm{g}}^{2} * \mathrm{~V}_{11}$

(5) $Z_{12, \mathrm{~g}}=\sigma_{a \beta, \mathrm{g}}+\sigma_{\varepsilon, \mathrm{g}}{ }^{2} * V_{12}$

(6) $Z_{22, \mathrm{~g}}=\sigma_{\beta, \mathrm{g}}{ }^{2}+\sigma_{\varepsilon, \mathrm{g}}{ }^{2} * V_{22}$

(7) $\mathrm{D}_{\mathrm{g}}=Z_{11, \mathrm{~g}}{ }^{\mathrm{\beta}} \mathrm{Z}_{22, \mathrm{~g}}-\mathrm{Z}_{12, \mathrm{~g}}{ }^{2}$

(8) $\mathrm{W}_{11, \mathrm{~g}}=Z_{22, \mathrm{~g}} / \mathrm{D}_{\mathrm{g}}$

(9) $\mathrm{W}_{12, \mathrm{~g}}=-\mathrm{Z}_{12, \mathrm{~g}} / \mathrm{D}_{\mathrm{g}}$

(10) $\mathrm{W}_{22, \mathrm{~g}}=\mathrm{Z}_{11, \mathrm{~g}} / \mathrm{D}_{\mathrm{g}}$

(11) $\mathrm{C}_{\mathrm{g}}=-1 / 2$ * $\left[\left(\mathrm{a}-\alpha_{\mathrm{g}}\right)^{2} \mathrm{~W}_{11, \mathrm{~g}}+2\left(\mathrm{a}-\alpha_{\mathrm{g}}\right)\left(\mathrm{b}-\beta_{\mathrm{g}}\right)\right.$ $\left.\mathrm{W}_{12, \mathrm{~g}}+\left(\mathrm{b}-\beta_{\mathrm{g}}\right)^{2} \mathrm{~W}_{22, \mathrm{~g}}+\ln \left(\mathrm{D}_{\mathrm{g}}\right)\right]$

(12) Discrimination score $=$ $\mathrm{C}_{\text {Marfan patients }}-\mathrm{C}_{\text {control subjects }}$

1 Lee B, Godfrey M, Vitale E, et al. Linkage of Marfan syndrome and a phenotypically related disorder to two different fibrillin genes. Nature 1991;352:330-4.

2 McKusick VA. The cardiovascular aspects of Marfan's syndrome: a heritable disorder of connective tissue. Circulation 1955;11:321-42.

3 Pyeritz RE, McKusick VA. The Marfan syndrome: diagnosis and management. N Engl f Med 1979;300:772-7.

4 Beighton P, de Paepe A, Danks D, et al. International nosology of heritable disorders of connective tissue, Berlin, 1986. Am F Med Genet 1988;29:581-94.

5 De Paepe A, Devereux RB, Dietz HC, et al. Revised diagnostic criteria for the Marfan syndrome. Am $\mathcal{F ~ M e d ~}$ Genet 1996;62:417-26.

6 Pyeritz RE. Disorders of fibrillins and microfibrilogenesis: Marfan syndrome, MASS phenotype, contractural arachnodactyly and related conditions. In: Emery AE, Rimoin DL, David L, et al, eds. Principles and practice of medical DL, David L, et al, eds. Principles and practice of medical
genetics, 3rd ed. New York: Churchill Livingstone, 1996. 
7 Morse RP, Rockenmacher S, Pyeritz RE, et al. Diagnosis and management of infantile Marfan syndrome. Pediatrics 1990;86:888-95.

8 Silverman DI, Burton KJ, Gray J, et al. Life expectancy in the Marfan syndrome. Am f Cardiol 1995;75:157-60.

9 Gott VL, Pyeritz RE, Cameron DE, et al. Composite graft repair of Marfan aneurysms of the ascending aorta: results in 100 patients. Ann Thorac Surg 1991;52:38-45.

10 Silverman DI, Gray J, Bridges A, et al. Family history of severe cardiovascular disease in Marfan syndrome is associated with increased aortic diameter and decreased survival. F Am Coll Cardiol 1995;26:1062-7.

11 Legget ME, Unger TA, O'Sullivan CK, et al. Aortic root complications in Marfan's syndrome: identification of a lower risk group. Heart 1996;75:389-95.

12 Oorthuys JWE, Naeff MSJ, Hennekam RCM, et al. Marfan syndrome: a multidisciplinary clinical study of 91 patients. Tijdschr Kindergeneeskd 1995;63:33-40.

13 Shores J, Berger KR, Murphy EA, et al. Progression of aortic dilatation and the benefit of long-term-adrenergic tic dilatation and the benefit of long-term-adrenergic 1335-41.

14 Salim MA, Alpert BS, Ward JC, et al. Effect of betaadrenergic blockade on aortic root rate of dilation in the Marfan syndrome. Am f Cardiol 1994;74:629-33.

15 Sheil MLK, Jenkins O, Sholler GF. Echocardiographic assessment of aortic root dimensions in normal children based on measurement of a new ratio of aortic size independent of growth. Am f Cardiol 1995;75:711-15.

16 Vasan RS, Larson MG, Levy D. Determinants of echocardiographic aortic root size. The Framingham heart study. Circulation 1995;91:734-40.

17 Henry WL, Gardin JM, Ware JH. Echocardiographic measurements in normal subjects from infancy to old age. Circulation 1980;62:1054-61.

18 Jeremy RW, Huang H, Hwa J, et al. Relation between age, arterial distensibility, and aortic dilatation in the Marfan syndrome. Am f Cardiol. 1994;74:369-73.

19 Roman MJ, Devereux RB, Kramer-Fox R, et al. Twodimensional echocardiographic aortic root dimensions in dimensional echocardiographic aortic root dimensions in

20 Roman MJ, Rosen SE, Kramer-Fox R, et al. Prognostic significance of the pattern of aortic root dilation in the Marfan syndrome. F Am Coll Cardiol 1993;22:1470-6.

21 Snider AR, Enderlein MA, Teitel DF, et al. Twodimensional echocardiographic determination of aortic and pulmonary artery sizes from infancy to adulthood in normal subjects. Am f Cardiol 1984;53:218-24.

22 Henry WL, Ware J, Gardin JM, et al. Echocardiographic measurements in normal subjects. Growth-related changes that occur between infancy and early adulthood. Circulation 1978;57:278-85.

23 Gutgesell HP, Rembold CM. Growth of the human heart relative to body surface area. Am f Cardiol 1990;65:662-8.

24 Reed CM, Richey PA, Pulliam DA, et al. Aortic dimensions in tall men and women. Am $\mathcal{F}$ Cardiol 1993;71:608-10.

25 Rogé CLL, Silverman NH, Hart PA, et al. Cardiac structure growth pattern determined by echocardiography. Circulation 1978;57:285-90.
26 Vetter U, Mayerhofer R, Lang D, et al. The Marfan syndrome-analysis of growth and cardiovascular manifestation. Eur f Pediatr 1990;149:452-6.

27 Geva T, Sanders SP, Diogenes MS, et al. Two-dimensional and Doppler echocardiographic and pathologic characteristics of the infantile Marfan syndrome. Am f Cardiol 1990; 65:1230-7.

28 Sahn DJ, DeMaria A, Kisslo J, et al. The committee on M-mode standardization of the American Society of Echocardiography. Recommendations regarding quar ion in $M-$ mode ion in M-modechocardiography: results of a survey of echocardiog $1072-83$.

29 Rozendaal L, Groenink M, Naeff MSJ, et al. Marfan syndrome in children and adolescents: an adjusted nomogram for screening aortic root dilation. Heart 1998;78:69-72.

$30 \mathrm{Du}$ Bois D, Du Bois EF. A formula to estimate the approximate surface area if height and weight be known. Arch Intern Med 1916;17:863-72.

31 Ichida F, Aubert A, Denef B, et al. Sectional echocardiographic assessment of great artery diameters in infants and children. Br Heart f 1987;58:627-34.

32 Jennrich RI, Schluchter MD. Unbalanced repeatedmeasures models with structured covariance matrices. Biometrics 1986;42:805-20.

33 Armitage P, Berry G, eds. Statistical methods in medical research, 2nd ed. Oxford: Blackwell Scientific Publications, 1987:334-6.

34 Hirata K, Triposkiadis F, Bowen J, et al. The Marfan syndrome: rate of aortic root dilatation [abstract]. Circulation 1989;80(suppl 2):2-529.

$35 \mathrm{El} \mathrm{Habbal} \mathrm{MH.} \mathrm{Cardiovascular} \mathrm{manifestations} \mathrm{of} \mathrm{Marfan's}$ syndrome in the young. Am Heart f 1992;123:752-7.

36 Geva T, Hegesh J, Frand $M$. The clinical course and echocardiographic features of Marfan's syndrome in childhood. Am f Dis Child 1987;141:1179-82.

37 Banki JH, Meiners LC, Barentsz JO, et al. Detection of aoric dissection by magnetic resonance imaging in adults with Marfan's syndrome. Int f Cardiac Imaging 1992;8:249-54.

38 Schlatmann TJM, Becker AE. Histologic changes in the normal ageing aorta: implications for dissecting aortic aneurysm. Am 7 Cardiol 1977;39:13-20.

39 Schlatmann TSJM, Becker AE. Pathogenesis of dissecting aneurysm of aorta. Comparative histopathologic study of significance of medial changes. Am f Cardiol 1977;39:21-6.

40 Hirata K, Triposkiadis F, Sparks E, et al. The Marfan syndrome: abnormal elastic properties. $\mathcal{F}$ Am Coll Cardiol 1991;18:57-63.

41 Adams JN, Brooks M, Redpath TW, et al. Aortic distensibility measured by magnetic resonance imaging in patients with Marfan's syndrome. Br Heart F 1995;73:265-9.

42 Reed CM, Fox ME, Alpert BS. Aortic biomedical properties in pediatric patients with the Marfan syndrome, and the effect of atenolol. Am $\mathcal{F}$ Cardiol 1993;71:606-8.

43 Lipscomb KJ, Clayton-Smith J, Harris R. Evolving phenotype of Marfan's syndrome. Arch Dis Child 1997;76:41-6. 